\title{
Critical Thinking and Clinical Judgment Skills for baccalaureate Nursing Students in EL-Minia University
}

Gabra ,Sh., F; Sadek , R., R; Mohamed , S., Abd Elr\& Mohamed , F ., R. Nursing Administration Department, Faculty of Nursing, EL- Minia University. Community Medicine Department, Faculty of Medicine, EL-Minia University. Nursing Administration Department, Faculty of Nursing, Assuit University.

\begin{abstract}
:
Background: Critical thinking and clinical judgment in nursing has been accentuated in response to the rapidly changing health care environment. Nurses must think critically and clinically judgment to provide quality of care and coping with the expansion in role associated with the complexities of current health care systems. Aim of the study: to assess critical thinking and clinical judgment skills for baccalaureate nursing students in EL-Minia University. Methodology: The study was developed within descriptive approach. Setting: The study was carried out at Faculty of Nursing in EL-Minia University. Subject: All Baccalaureate nursing students at Faculty of Nursing in EL-Minia University in the academic year 2010/2011 with total number $(\mathrm{n}=105)$. Tools of study: The study tools were two the first tool for critical thinking consisted of two parts 1st part related to socio demographic characteristics sheet \&2ndpart was the California Critical Thinking Disposition Inventory (CCTDI), Second tool for clinical judgment. Results: There were no statistically significant differences between demographic characteristics (sex\& residence) with critical thinking and clinical judgment items. Conclusions: The rate of urban and male student nurses were had high level in the total score of critical thinking. Moreover, rate of rural and female student nurses were had middle to high level in the total score of clinical judgment. Recommendations: Attending of nursing teachers a training program about how to identifying teaching strategies needed and how to use these strategies in effective ways for the development of critical thinking and clinical judgment skills for nursing students.
\end{abstract}

\section{Keywords: Critical Thinking, Clinical Judgments, Nurse Students.}

\section{Introduction:}

Critical thinking and clinical judgment have been identified as essential skills for practicing professional nurses (American Association of Colleges of Nursing, (2008). Nurses utilize critical thinking and clinical judgment in their practice every day. They are presented with information provided by the client, assessment findings, clinical lab reports as well as implementing physicians' orders for each client. The nurse must distinguish normal versus abnormal findings, validate findings, group relevant from irrelevant information, recognize inconsistencies, identify patterns, prioritize the findings, develop hypotheses, and act upon the findings (Cruz et al ., 2009). Critical thinking has gained attention in recent decades as a goal of higher education in the United States. Many colleges and universities articulate critical thinking as an intended objective of teaching and learning in institutional mission statements and publications (Barnes, 2005). In practice discipline such as nursing, critical thinking is considered essential to the provision of safe, appropriate, relevant care to clients in variety of setting. The importance of critical thinking is inextricably related to the complexity of the current health care environment and ever changing and expanding technologies are required for effective clinical judgment and decision making (Brunt,
2005). Health care professionals today's are faced with the demands to keep best practices in caring their patients (Hynes \& Bennet, (2004). Critical thinking is essential in the professional practice of nurses because nurses are expected to make timely judgments and decisions rooted in reason and those decisions must be sound (Evancho, 2000). The development of critical thinking is dependent on both facilitating critical thinking dispositions and by utilizing active learning (cooperative strategies which incorporate specific thinking skills and decisions that can be practiced and refined in the classroom (Coluciello, 1999).The concept of critical thinking encompasses problem solving, decision making, clinical judgment and creativity; clinical judgment is the ability to make inference from data gathered during the problem solving process (Loving, 1993). According to, (Alfora, (2002) critical thinking must be viewed as being more than a problem solving method. Nurses in professional practice use critical thinking and clinical judgment on a daily basis in all aspects of their practice. The nursing clinical reasoning process is the format that guides nurses in their decisions. Nursing clinical reasoning involves assessment, diagnosis, outcome identification, planning, implementation, and evaluation. At each phase nurses must assess and evaluate how well the client is functioning, and meet the client's healthcare 
needs (Jarvis, 2008).Critical thinking and clinical judgment skills are important for nurses in the present nursing area. Nurses need to critical thinking and clinical judgment skills to be able to deliver safe, effective and efficient client care in today's complex health care system. Safe and effective nursing care is essential for both the client's well being and the organization's potential liability. Nurse's critical thinking can effect health promotion, prevention of complication, avoidance of hospitalization or decreased length of hospitalization and even make a difference in life or death (Thiele, 1986).Clinical judgment has identified as outcomes of critical thinking in nursing practice (American Association of Colleges of Nursing (AACN) (2008). Nurses must possess good critical thinking skills in order to make valid and appropriate clinical judgments in practice (National League for Nursing Accrediting Commission (NLNAC), (2002).Nursing programs educate nursing students to think critically as part of their Accreditation requirements. In addition, the NLNAC does not specify how nursing programs are to accomplish this task, but leaves it to the individual nursing programs to define, teach and evaluate these skills. As a result, there have been numerous ongoing revisions of nursing curricula within nursing programs as they struggle to meet this mandate and successfully teach critical thinking skills to students (Miller, 2005).

Significance of the study:

Nurses in clinical practice continually make judgment and decisions based on the assessment and diagnosis of patient needs. Moreover, there has been growing concern in nursing as a result of the recent changes in the health care environment. In nursing practice, it is valuable for nurses to use their critical thinking and clinical judgments skills in a variety of ways. Critical thinking skills help the professional nurse to make important judgments and decisions after collection and interpretation of the information needed to make decisions. The undergraduate nurse should be enabling to have critical thinking and clinical judgments skills that will help them after graduation as a professional nurse. So, the researcher decided to assess critical thinking and clinical judgment skills among nurse students at Faculty of Nursing in EL- Minia University.

Aim of the study:

This study was carried out with the aim of assessing critical thinking and clinical judgment skills for baccalaureate nursing students in EL-Minia University.

Subject and methods:

1-Technical design: This design involves the research design, setting, subject, and tools of data collection.
Research Design: The present study was carried out using a descriptive study design.

Setting: The study was conducted in Faculty of Nursing at EL-Minia University. Faculty of nursing consisted of five nursing laboratories, Faculty included six departments as the following , Department of Medical and Surgical Nursing with total number twenty eight of staff members, Department of Maternity and Gynecology Nursing with total number of fifteen staff members, Department of pediatric nursing with total number of thirteen staff members, Department of Psychiatric and Mental Health Nursing with total number of twelve staff members, Department of Nursing Administration with total number of seventeen staff members, and Department of Community Health Nursing with total number of eleven staff members.

\section{Subject:}

Subject of the present study included all baccalaureate nursing students at Faculty of Nursing in EL-Minia University in the academic year 2010/2011.The total sample size was $(\mathrm{N}=105)$.

Data collection tools:

Two tools were used to collect study data includes:-

First tool for critical thinking include:

1st Part socio demographic characteristics sheet:

It included items related to the subjects such as gender, age and residence.

N.B: Student's ages are approximately similar.

2nd Part the California Critical Thinking Disposition Inventory (CCTDI ).It adopted from (Nagib R, 2008) and the researcher used it to collect data concerning the disposition of baccalaureate nursing students towards critical thinking, at Faculty of Nursing in ELMinia University. The tool consisted of seventy five items grouped into seven dispositional factors : (a) truth seeking (12 items), (b) open-mindedness (12 items), (c) analyticity (11 items), (d) systematicity (11 items), (e) self-confidence (9 items), (f) inquisitiveness (10 items) and (g) cognitive maturity (10 items). All items of the seven dispositional characteristics with scoring system are four points likert scale ranging from "strongly agree (4)" to" strongly disagree "(1).Total score of the questionnaire are classified into three levels first level mild ranged from (75-150), second level moderate ranged from (151-225), and third level high ranged from (226-300) Second tool for clinical judgment: It developed by (Janis and Mann, 1977), It used to collect data concerning the assessment of baccalaureate nursing students clinical judgment. It consisted of(40 Items) grouped into four factors are (a) search for alternatives or options(3 items, 10 sub items), (b) canvassing of objectives and values ( 3 items, $10 \mathrm{sub}$ items), (c) evaluation and reevaluation of consequences (2 items, 10 sub items), (d) search for 
information and unbiased assimilation of new information ( 3 items, 10 sub items). All items of the four areas with scoring system are three points likert scale ranging from "agree (3)" to" disagree "(1). Total score of the questionnaire are classified into two levels first level low to middle ranged from (40-80), and second level middle to high ranged from (81140).

Administrative design: Approval to carry out the study was obtained from the Dean of Faculty of Nursing in EL-Minia University and Head of Nursing Administration Department to collect the necessary data for the study.

\section{Operational design:}

Preparation phase: This phase took three months from January to March 2011 the researcher spent this time in reviewing the available literature concerning the topic of the study and Arabic translation of the clinical judgment tool was done .

Ethical considerations: Oral agreement was taken from the participants (Baccalaureate nursing students). Confidentiality of obtained data was assured, the nature, and the aim of the study was explained to all participating nursing students before starting data collection.

Pilot study: A pilot study was carried out to assess tools clarity and applicability. Moreover, to identify problems that may be encountered during the actual data collection. It applied for eleven students from
Faculty of Nursing in EL-Minia University that constituted the subjects of our study. Data collected from the pilot study was analyzed by using SPSS version 16 (Statistical Package for Social Science). No changes were done after the pilot study, so the nurse students included in the pilot study were included in the total study subjects. The reliability Alpha co-efficient of the total clinical judgment tool was $(\alpha=0.95)$, which is highly reliable.

\section{Data Collection:}

The researcher met with each subject in the study to explain the aim of the study and to ask for participation. The study tools handles to participated student to be filled. The data collection was done through self-administered questionnaires with participants to be filled the forms. The study tools took about twenty minutes for each one to be filled .The present study carried out within about three months started from March to May 2011.

\section{Statistical design:}

Data entry and analysis were done using SPSS version 16 (Statistical Package for Social Science). Data were presented using descriptive statistics in the form of frequencies, percentages, and chi-square. Pearson correlation analysis was used for assessment of the interrelation among quantitative variable. Statistical significance was considered at $\mathrm{p}$ - value $\leq$ 0.05 .

\section{Result:}

Table (1): Distribution of Socio-demographic characteristics among baccalaureate nursing students at ELMinia University (sex\&residence).

\begin{tabular}{|c|c|c|c|c|c|c|c|c|}
\hline \multirow{2}{*}{$\begin{array}{l}\text { Demographic } \\
\text { characteristics }\end{array}$} & \multicolumn{2}{|c|}{ Rural } & \multicolumn{2}{|c|}{ Urban } & \multicolumn{2}{|c|}{ total } & \multirow{2}{*}{$X^{2}$ test } & \multirow{2}{*}{$p$-value } \\
\hline & No. & $\%$ & No. & $\%$ & No. & $\%$ & & \\
\hline \multicolumn{7}{|l|}{ Sex } & \multirow{4}{*}{1.48} & \multirow{4}{*}{0.22} \\
\hline Male & 26 & 66.6 & 13 & 33.3 & 39 & 37.1 & & \\
\hline Female & 36 & 54.5 & 30 & 45.5 & 66 & 62.9 & & \\
\hline Total & 62 & 59.0 & 43 & 41.0 & 105 & 100 & & \\
\hline
\end{tabular}

Table (2): Relation between total scores levels of critical thinking and clinical judgment according to sex\& residence among baccalaureate nursing students at EL-Minia University $(n=105)$.

\begin{tabular}{|c|c|c|c|c|c|c|c|c|c|c|c|c|}
\hline \multirow[t]{2}{*}{ Items } & \multicolumn{2}{|c|}{$\begin{array}{c}\text { Rural } \\
(N=62)\end{array}$} & \multicolumn{2}{|c|}{$\begin{array}{l}\text { Urban } \\
(N=43)\end{array}$} & \multirow{2}{*}{$X^{2}$} & \multirow{2}{*}{$\begin{array}{c}P \\
\text { value }\end{array}$} & \multicolumn{2}{|c|}{$\begin{array}{c}\text { Male } \\
(N=39)\end{array}$} & \multicolumn{2}{|c|}{$\begin{array}{c}\text { Female } \\
(N=66)\end{array}$} & \multirow[t]{2}{*}{$X^{2}$} & \multirow[t]{2}{*}{$\begin{array}{c}P \\
\text { value }\end{array}$} \\
\hline & No. & $\%$ & No. & $\%$ & & & No. & $\%$ & No. & $\%$ & & \\
\hline \multicolumn{13}{|c|}{ Total Score Levels of Critical Thinking } \\
\hline Moderate & 20 & 32.3 & 12 & 27.9 & \multirow{2}{*}{0.227} & \multirow{2}{*}{0.634} & 11 & 28.2 & 21 & 31.8 & \multirow{2}{*}{0.151} & \multirow{2}{*}{0.698} \\
\hline High & 42 & 67.7 & 31 & 72.1 & & & 28 & 71.8 & 45 & 68.2 & & \\
\hline \multicolumn{13}{|c|}{ Total score levels of clinical judgment } \\
\hline Low to & 14 & 22.6 & 12 & 27.9 & 0.387 & 0.534 & 13 & 33.3 & 13 & 19.7 & 2.447 & 0.118 \\
\hline
\end{tabular}




\begin{tabular}{|c|c|c|c|c|c|c|c|c|c|c|c|c|}
\hline \multirow[t]{2}{*}{ Items } & \multicolumn{2}{|c|}{$\begin{array}{c}\text { Rural } \\
(N=62)\end{array}$} & \multicolumn{2}{|c|}{$\begin{array}{c}\text { Urban } \\
(N=43)\end{array}$} & \multirow{2}{*}{$X^{2}$} & \multirow{2}{*}{$\begin{array}{c}P \\
\text { value }\end{array}$} & \multicolumn{2}{|c|}{$\begin{array}{c}\text { Male } \\
(N=39)\end{array}$} & \multicolumn{2}{|c|}{$\begin{array}{c}\text { Female } \\
(N=66)\end{array}$} & \multirow[t]{2}{*}{$X^{2}$} & \multirow[t]{2}{*}{$\begin{array}{c}P \\
\text { value }\end{array}$} \\
\hline & No. & $\%$ & No. & $\%$ & & & No. & $\%$ & No. & $\%$ & & \\
\hline \multicolumn{11}{|l|}{ middle } & & \\
\hline $\begin{array}{l}\text { Middle to } \\
\text { high }\end{array}$ & 48 & 77.4 & 31 & 72.1 & & & 26 & 66.7 & 53 & 80.3 & & \\
\hline
\end{tabular}

Table (3): Correlation between critical thinking and clinical judgment among baccalaureate nursing students at EL-Minia University according to sex\& residence $(n=105)$.

\begin{tabular}{|c|c|c|c|c|c|c|c|c|}
\hline Variables & \multicolumn{2}{|c|}{$\begin{array}{c}\text { Male } \\
(n=39)\end{array}$} & \multicolumn{2}{|c|}{$\begin{array}{c}\text { Female } \\
(n=66)\end{array}$} & \multicolumn{2}{|c|}{$\begin{array}{r}\text { Rural } \\
(n=62)\end{array}$} & \multicolumn{2}{|c|}{$\begin{array}{l}\text { Urban } \\
(n=43)\end{array}$} \\
\hline Correlation & $\mathrm{r}$ & P-value & $\mathrm{r}$ & P-value & $\mathrm{r}$ & P-value & $\mathrm{r}$ & P-value \\
\hline $\begin{array}{l}\text { thinking \&clinical } \\
\text { judgment }\end{array}$ & 0.428 & $0.007 * *$ & 0.334 & $0.006^{* *}$ & 0.320 & $0.011 *$ & 0.394 & $0.009 * *$ \\
\hline
\end{tabular}

** Statistically significant at 0.001

* Statistically significant at $\quad 0.005$

Table (1) Distribution of socio-demographic characteristics among baccalaureate nursing students at EL-Minia University is illustrated in table (1). As table illustrates about two thirds of study subject were female $(62.9 \%)$, while only about more than one third of study subject were males $(37.1 \%)$, and more than half of the study subject were from rural (59\%), while, $(41.0 \%)$ of study subject were from urban. There were no statistically significant differences between male and female baccalaureate nursing students with their residence.

Table (2) Relation between total scores levels of critical thinking and clinical judgment according to sex\& residence among baccalaureate nursing students at EL-Minia University is illustrated in table (2). As table displays the rate of urban students nurses were more than rural students nurses had high level in total score levels of critical thinking $(72.1 \%, 67.7 \%)$ respectively, the rate of male students nurses were more than female students nurses had high level in total score levels of critical thinking $(71.8 \%, 68.2 \%)$ respectively. While, the rate of rural students nurses were more than urban students nurses had middle to high level in total score levels of clinical judgment $(77.4 \%, 72.1 \%)$ respectively, the rate of female students nurses were more than male students nurses had middle to high level in total score levels of clinical judgment $(80.3 \%, 66.7 \%)$ respectively. There were no statistically significant differences between total score levels of critical thinking and clinical judgment according to sex $\&$ residence.

Table (3) Correlation between critical thinking \&clinical judgment among baccalaureate nursing students at EL-Minia University according to sex\& residence is illustrated in table (3).As table shows female's students had positive correlation more than males, and students from urban had positive correlation more than from rural. There were statistically significant differences between critical thinking and clinical judgment according to sex and residence $\left(0.007 * *, 0.006^{* *}, 0.011^{*}, 0.009^{* *}\right)$.

\section{Discussion:}

Today's need for teaching thinking is created by the rapid changes taking place in society. Knowledge and information are becoming even more complex and soon may become dated. Nursing educators in response to the rapidly changing health care environment has emphasized the need for critical thinking in nursing education. Accordingly, the development of critical thinking among undergraduate nursing students has become a vital educational goal and the focus of research on undergraduate education (Drennan, 2010). Critical thinking and clinical judgment have been identified as essential skills as part of professional nursing practice. However, measuring these skills remains a challenge (Walsh \& Seldomridge, 2006). Critical thinking skills are important because they enable students to deal effectively with social, scientific, and practical problems (Shakirova, 2007). To be effective in the workplace (and in their personal lives), students must be able to solve problems to make effective judgments and decisions; they must be able to think critically (Scriven \& Poul, 2007).

Therefore, this study was conducted to assess critical thinking and clinical judgment skills for baccalaureate nursing students in EL-Minia University.

In the present study, about two thirds of the study subjects were females. This results might be attributed to the fact that the majority of nurses who 
graduated from secondary diploma school and clinical institute complete in nursing faculty were females and society view about nursing occupation is appropriate to females more males (Table, 1). This was supported by (Walling, 2011) who mentioned that while the proportion of men entering the nursing profession has been growing, it remains a female-dominated occupation.

More than half of the study subject was from rural (table, 1). This result was consistent with (Almaty, 2006) who clarified that increased unemployment, decreasing incomes and increasing costs of living had all resulted in a surge in poverty and a general decline in living conditions of the rural population, particularly of rural women. These developments had triggered increased income and searching for a governmental job to improve socioeconomic status.

As regard to present study, the rate of urban student's nurses were had high level in total score of critical thinking than rural student's nurses (Table, 2). This result might be attributed to urban students' have different style of life and modern media that help to collect information that lead to improve thinking. This finding was supported by (Michael, 2002) who concluded that using the computer and other technology as tools for meaningful projects seems reasonable as a method for engaging students in problem solving and critical thinking.

In the present study, the rate of male students nurses were had high level in total score levels of critical thinking than female students nurses (Table, 2).This result might be due to our community culture give males chances to learn and think more females and to carry out responsibility. This result was supported by (Mohammad \&Akram, 2011) who justified that male better than females in critical thinking. Also, on the other hand, (Sue, 2005) stated that male was more likely than females to participate in the advanced mathematics-physical sciences and the technical vocational courses which improve thinking. Females were more likely to be enrolled in social sciences and humanities, arts, and the service-clerical vocational which improve ability to judge.

In the present study, the rate of rural students' nurses were more than urban students' nurses in middle to high level in total score levels of clinical judgment (Table, 2). This result might be attributed to that students from rural have psychological stability more than students from urban. This result was consistent with (Fiona \&Henry, 2002) who justified that urban living is a risk factor for the development of psychiatric disorders, particularly depression, anxiety and stress which affect on judgment. By contrast, rural areas have been depicted an environment of social stability, integration and supportive interpersonal networks which lead to effective clinical judgment and decision.

Also, this result was consistent with (Everett \&Rabel, 2004) who added that rural people tend to live, works, and decide independently and they are involved in every judgment and decision, great or small.

The rate of female students' nurses more than male student's nurses in middle to high level in total score of clinical judgment

(Table, 2). This result was supported by (Viswanath, 2006) who showed that women often like to discuss options more interested, and more concentrated before reaching judgment then a decision. While, men seem too more rapid in judgment and decision. Also, women now have easier access to information, their own finances, and a sense of control over their own lives; many are making their own clinical judgments and decisions effectively. While, this result is inconsistent with (Michael et al., 2000) who stated that men when compared to women's judges or decisions, the judgments and decisions of men were more strongly influenced by their attitude toward using the new technology. In contrast, women were more strongly influenced by subjective norm and perceived behavioral control.

In the present study, there were statistically significant differences and positive correlation between critical thinking and clinical judgment regardless of sex and residence (Tables 3 ). This result was consistent with (Bowles, 2000) who stated that critical thinking were positively correlated to clinical judgment. A significant relationship was found between critical thinking and clinical judgment. In addition (Patricia et al., 2009) who stressed that there was statistically significant difference and positive correlation between critical thinking \&clinical judgment.

In contrary with (Mann, 2010) who stated that, there was no significant relationship between critical thinking and clinical judgment.

Overall, in the current study, Females 'students had positive correlation and statistically significant difference more than males (Table, 3).This result might be attributed to female's students more interest and curious to know the new things and need for a variety action. This finding was supported by (Graham \&Donaldson, 2004) who stressed that there is a relation between the developments of critical thinking, creativity, judgments and problem solving of females to their higher interest to know. Also, this result might be due to females students' better communicator and make relationship than males. This in agreement with (Yang \& Jung, 2004) who added that clinical judgment and decisionmaking is particularly influenced by interpersonal 
relationships and communication with others. While, this result was inconsistent with (Schaffer \& Rubenfeld, 2000) who pointed out that women had score higher than men on stress level and stressful situations produce fuzzy, illogical thinking, confusion and fears of being unable to achieve effective clinical judgment and decision.

In the present study, students from urban had positive correlation and statistically significant difference more than from rural (Table, 3).This may be attributed to the way of raising people in urban which give them a chance to share in many activities and easy to reach different facilities and media as cinema, TV, internet....etc .This finding was supported by (Sharee, 2004) who clarified that media literacy education helps to gather information that develop critical thinking and active participation in our clinical judgments and decisions.

\section{Conclusion:}

In the light of the study results, the following conclusions can be drawn:

The rate of urban and male student nurses were had high level in the total score of critical thinking. Moreover, rate of rural and female student nurses were had middle to high level in the total score of clinical judgment.

\section{Recommendations:}

Based on the most important findings of the present study, the following recommendations were suggested:

1) Nursing curriculum should be revised to include critical thinking, clinical judgment, and decision making skills into all levels of nursing curriculum and perceiving critical thinking and clinical judgment and decision as an independent unit to be taught.

2) Nurse educators must try new teaching approaches and establish those teaching strategies that are most effective in promoting critical thinking and clinical judgment skills among students.

3) More clinical training is needed to facilities the development of students' critical thinking, clinical judgment, and decision making abilities through providing multiple different clinical settings.

4) Attending of nursing teachers a training program about how identifying teaching strategies needed and how to use these strategies in effective ways for the development of critical thinking and judgment skills in nursing students.

5) Number of clinical instructors and nursing educators should be increased to meet needs of student nurse to improve critical thinking, clinical judgment and decision.

6) A similar study should be replicated in others universities (nursing faculties) in Egypt to validate theses findings.

\section{References:}

1. Alfora. L., (2002): Letter to editor of AACN news. Retrieved January17.2006,from http://www.aacn.Org/AACN/aacnnews.nsf/Geta rticle/ two199. Semel E, Wiig E, Secord W. (2000): Clinical Evaluation of Language Fundamentals. The Psychological Corporation. San Antonio UK, $3^{\text {rd }}$ ed. (CELF-3UK), P.p.316.

2. Almaty. K., (2006): Report of the Expert Group Meeting on Strengthening Generating Opportunities for Rural in Selected Central Asian Republics, P.62.

3. American Association of Colleges of Nursing, (2008): the essentials of Baccalaureate education for professional nursing practice. Washington, D.C.: Author.

4. American Association of Colleges of Nursing, (2008): the essentials of Baccalaureate education for professional nursing practice. Washington, D.C.: Author.

5. Barnes. C., (2005): Critical thinking revisited: Its past, present, and future. In S.M. Flores (Series Ed.) The Unfinished Business of Critical Thinking: New Directions for Community Colleges (No. 130, 5-13). San Francisco: JosseyBass.

6. Bowles.K., (2000): The relationship of criticalthinking skills and the clinical-judgment skills of baccalaureate nursing students. Journal of Nursing Education, 39(8), Pp.373-376.

7. Brunt.B., (2005): Critical thinking in Nursing: An Integrated Review Journal of Continuing Education in Nursing - Volume 36 - Issue 2, Pp. 60-67.

8. Coluciello. M., (1999): Relationship between critical thinking disposition and learning styles .journal of professional nursing 15(5) ,Pp.294307.

9. Cruz, D., Pimenta.C., \& Lunney. M., (2009): Improving critical thinking and clinical reasoning with a continuing education course. The Journal of Continuing Education in Nursing, 40(3), Pp.121-127.

10. Drennan. J., (2010): Critical thinking as an outcome of undergraduate nursing students. Journal of Advanced Nursing 66(2), Pp. 422431. 
11. Evancho.S., (2000): Critical thinking skills and dispositions of the undergraduate nursing student (Masters' thesis, Southern Connecticut University, 2000).Dissertations Abstracts International, 38 (05), P.1293.

12. Everett. R., \& Rabel. B., (2004): Contrasting Rural and Urban, volume 13(2), P. 267.

13. Fiona. K., Henry. J., (2002): High prevalence disorders in urban and rural Communities, Journal of Psychiatry, volume 9, issue 3, P. 104.

14. Graham. S., \& Donaldson. J., (2004): Adult students' academic and intellectual development in college. Adult Education Quarterly, 49, Pp.147-161.

15. Hynes. R., \& Bennet. J.,(2004): About critical thinking. Canadian. Associations of critical care nurses, 15 (3), Pp. 26-29.

16. Jarvis.C., (2008): Physical examination and health assessment (5th Ed). St. Louis, MO: Elsevier. 15 (3),Pp. 23-49.

17. Loving. G., (1993): Competence validation and cognitive flexibility: theoretical model granded in nursing education. Journal of nursing education; 32(9)415-423.

18. Mann, J., (2010): Promoting Curriculum Choices: Critical Thinking and Clinical Judgment Skill Development in Baccalaureate Nursing Student, available @ 10-Jul-2010. http://hdl.handle.net/1808/6742

19. Michael, G., Morris.D., Phillip. L., (2000): A Longitudinal Field Investigation of Gender Differences in Individual Technology Adoption Decision-Making Processes, Volume 83, Issue 1, September 2000, Pp.33-60..

20. Michael, H., (2002): Using a TechnologyEnriched Environment to Improve Higher-Order Thinking Skills, Journal of Research on Technology in Education Volume 34 Number 2, Pp. 109,

21. Miller. M., (2005): Critical thinking in the nursing curriculum. Nursing and Health Care, 11(2), 67-73.

22. Mohammad.A., \& Akram .S., (2011): Investigation of the Relationship between Gender, Field of Study, and Critical Thinking Skill: the Case of Iranian Student.

23. National League for Nursing Accrediting Commission (2002): The accreditation manual and interpretive guide lines by program type,RetrievedJanuary 17,2006,fromhttp://www .ntn.org/testprods/guideinterpretation.htm score report.

24. Patricia.B., Ronda. G., Hughes.A., Molly. S., (2009): Clinical Reasoning, Decision-making, and Action: Thinking Critically and Clinically,
Patient Safety and Quality: An Evidence-Based Handbook for Nurses, 11(4): Pp.67-73.

25. Scheffer. B.,\& Rubenfeld.M., (2000): A consensus statement on critical thinking in nursing. Journal of Nursing Education, 39(8), 352-359.

26. Scriven. M., \& Poul. R., (2007): Critical thinking defined. Handout given at critical thinking conference, Atlanta, GA.

27. Shakirova. D., (2007): Technology for the Shaping of College Students' and Upper-Grade Students' Critical Thinking. Russian Education \& Society, 49(9), Pp.42-52. Retrieved from Academic Search Premier Database.

28. Sharee.W., (2004): Introduction to Media Literacy, Available @ http://creativecommons.org/licenses/by-ncsa/3.0/us/,PP.2.

29. Sue. T., (2005): Pathways from school to further education or work examining the consequences of year 12 course choices. Available @ http:// research.acer.edu.au/lsay_research/46.

30. Thiele. J., (1986): An investigation of decision theory what are the effects of teaching cue recognition? Journal of Nursing Education, 25, pp.319-324.

31. Viswanath. V., (2006): Gender Roles in Decision Making, Available @ http://www.decision-makingconfidence.com/gender-differences-in-decisionmaking.html

32. Walling. P., (2011): How did Nursing Become a Female Profession available @ http://www.themale-nurse.com/2011/06/how-did-nursingbecome-female.html

33. Walsh. C., \& Seldomridge. L., (2006): Critical thinking: back to square two. Journal of Nursing Education, 45(6), Pp.212-220

34. Yang.S., \&Jung.D., (2004): A study on the critical thinking disposition about student nurse. J Korean Academy Adult Nurse; 16:156- 165. 